THE KURUME MEDICAL JOURNAL Vol. 18, No. 2, 1971

\title{
A PECULIAR CRYSTALLINE STRUCTURE IN NEURONS OF RABBITS TREATED WITH VINCRISTINE
}

\author{
KEN KOTORII, HIRONORI MORI AND MASATAKE YOSHIDA \\ Department of Neuropsychiatry, Kurume University School \\ of Medicine, Kurume, Japan
}

(Received for publication January 4, 1971)

\begin{abstract}
A peculiar structure has been demonstrated in neurons of rabbits treated with vincristine using electron microscope. The structure has a crystalline form such as honeycomb like pattern or highly regular arrays of electron dense line, and a variety of profiles depend upon the plane of section. The possible origin and nature of neuronal crystalline structure were discussed.
\end{abstract}

In the course of an electron microscopic study of experimental neurofibrillary degeneration induced by vincristine, the authors encountered a peculiar structure revealing a crystalline appearance as well as neurofibrillary change in neuron of rabbits. One of us (H.M.) ${ }^{10)}$ has previously reported ultrastructural changes especially in reference to neurofibrillary degeneration. This time attention will, therefore, be directed to the neuronal crystalline mass. The present paper describes ultrastructural finding in details and discusses the origin and nature of them.

\section{MATERIAL AND METHODS}

Twenty white male rabits, weighing 2000 to $2300 \mathrm{gm}$, were injected intracisternally with vincristine sulfate (Oncovin) in dose of $0.2 \mathrm{mg} / \mathrm{kg}$.

They were sacrificed at interval of 2 to 5 days after administration of vincristine. Under chloroform anesthesia their brain were perfused in situ with glutaraldehyde which were injected through a large needle into the aorta by way of left ventricle. The fixative used was a 5 per cent glutaraldehyde in a phosphate buffer at $\mathrm{pH}$ 7.4. After perfusion, the brain and spinal cord were removed and cut into $1 \mathrm{~mm}$ thick slice. The blocks were then postfixed for 2 hours in the cold with 2 per cent osmium tetroxide in phosphate buffered according to Millonig ${ }^{9)}$. Dehydration was accomplished by rapid changes of increasing concentration of ethanol solution (40 to 100 per cent). The blocks were embedded in epon using the method of Luft $^{8)}$. Ultrathin sections were cut with grass knives on a LKB ultramicrtome and were placed on the uncoated grids. After staining by uranyl acetate and lead tartrate, the electron micrographs were taken with Hitachi $11 \mathrm{~A}$ operating at $75 \mathrm{KV}$. Four untreated normal rabbits of the same age from which adequetely fixed brain were obtained, were used as control. 


\section{RESULTS}

These peculiar structures demonstrated here were frequently obseved in neuron of vincristine treated rabbits. Their topographical frequency is set out in the table. Most of the crystalline masses were found in area below pons.

TABLE 1

The Frequency of Crystal

\begin{tabular}{l|c|c}
\hline & $\begin{array}{l}\text { No. of Blocks } \\
\text { Examined }\end{array}$ & $\begin{array}{l}\text { No. of Blocks } \\
\text { Containing } \\
\text { Crystal }\end{array}$ \\
\hline $\begin{array}{c}\text { Cerebral Cortex } \\
\text { (Pre-Central) } \\
\text { Cerebellum }\end{array}$ & 10 & 1 \\
Pons & 7 & 0 \\
$\begin{array}{c}\text { Medulla } \\
\text { Oblongata }\end{array}$ & 9 & 7 \\
$\begin{array}{c}\text { Anterior Horn } \\
\text { Cell }\end{array}$ & 10 & 9 \\
\hline
\end{tabular}

They occurred only in the neuron including the perikarya, axon and synapse. Crystals, although encountered in all part of neuron, were aboundant in the myelinated axon. They showed well defined rhombohedral shapes in outline, and fairly large in size, measuring up to $7 \mu$ in lengh.

The structure displayed a crystalline pattern and a variety of profiles was observable in accordance with direction of the sections. Section perpendicular to the long axis of these crystalline bodies appeared to be regular pattern of circles. The great regularity of circular or polygonal profiles resembling a honeycomb, was most striking in true transverse section of myelinated axon. In higher magnification, some of them composed of a hexogonal electron lucent central space surrounded by an osmiophilic rim of even width. The greatest diameter of each hexogonal subunits was approximately 270 to $300 \AA$.

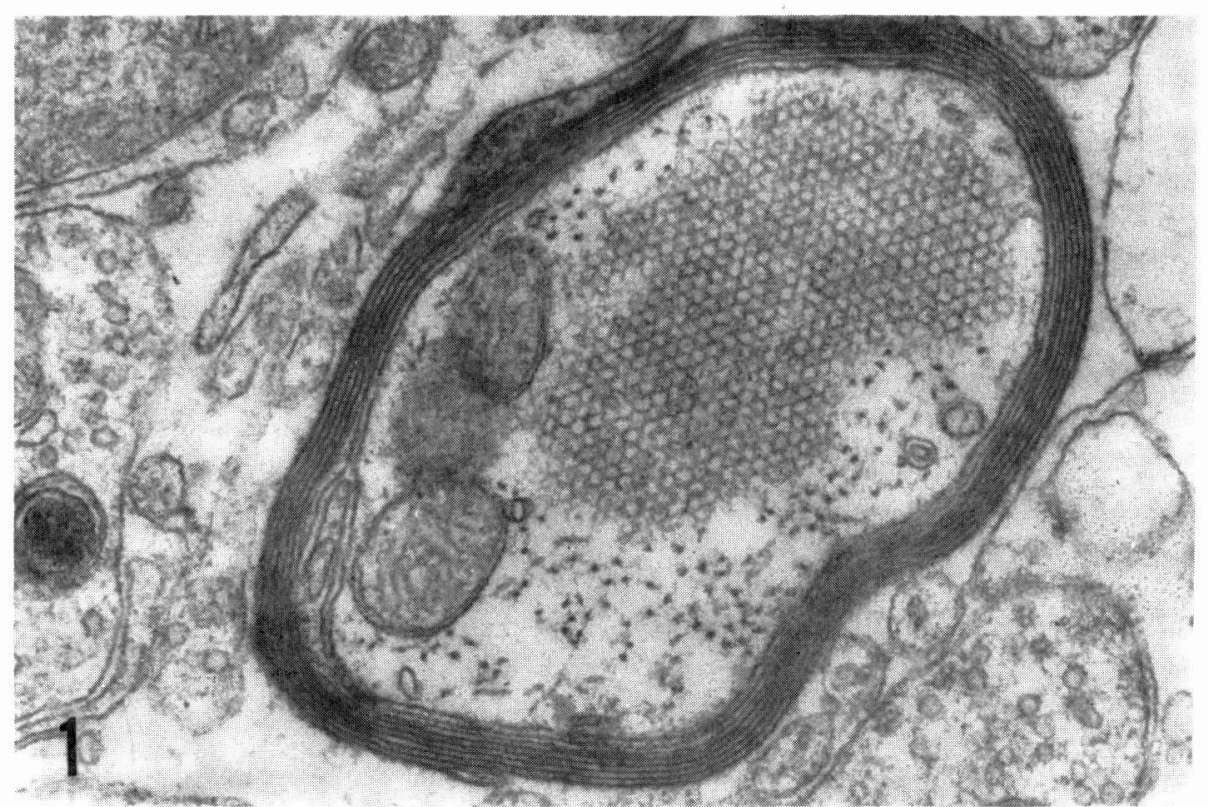

Fig. 1 Myelinated axon in the pons. A honeycomb-like stracture is evident within the axoplasm. $\times 48,000$ 


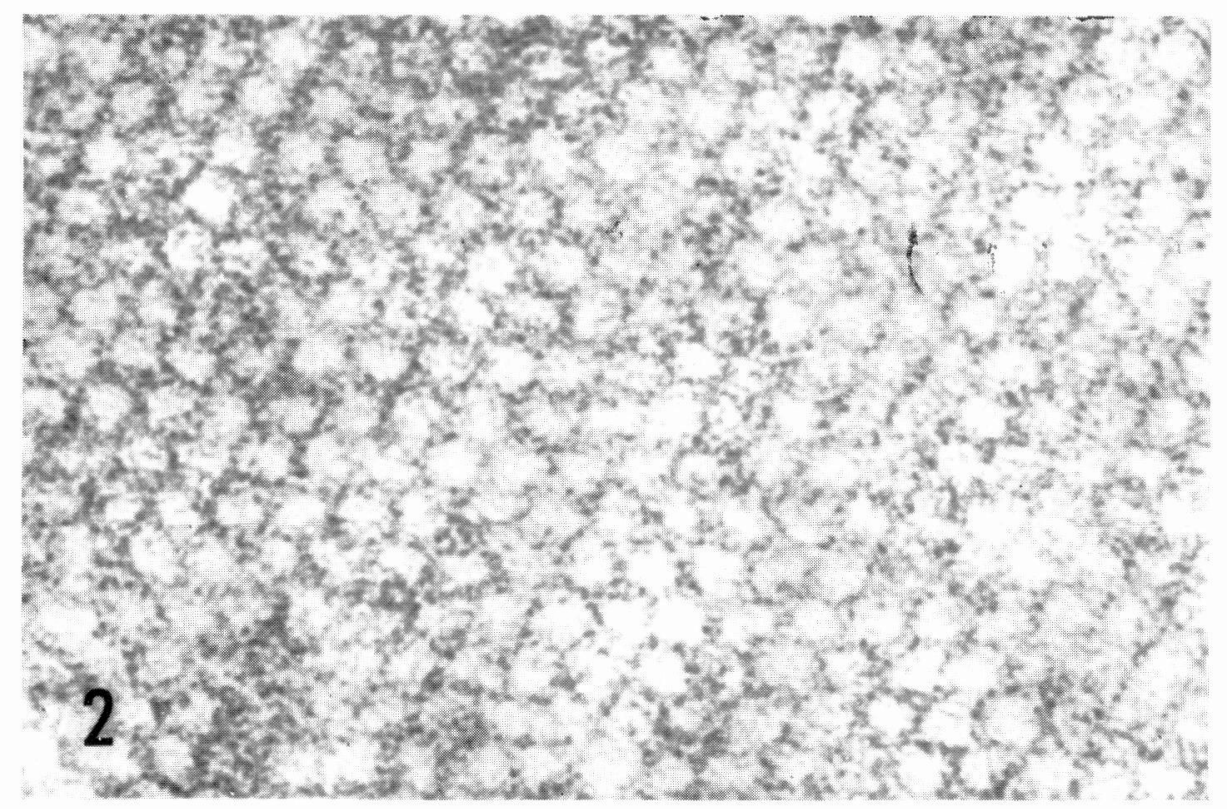

Fig. 2 Higher magnification of Fig. 1. Cross sectioned crystal showing the hexogonal subunits. $\times 180,000$

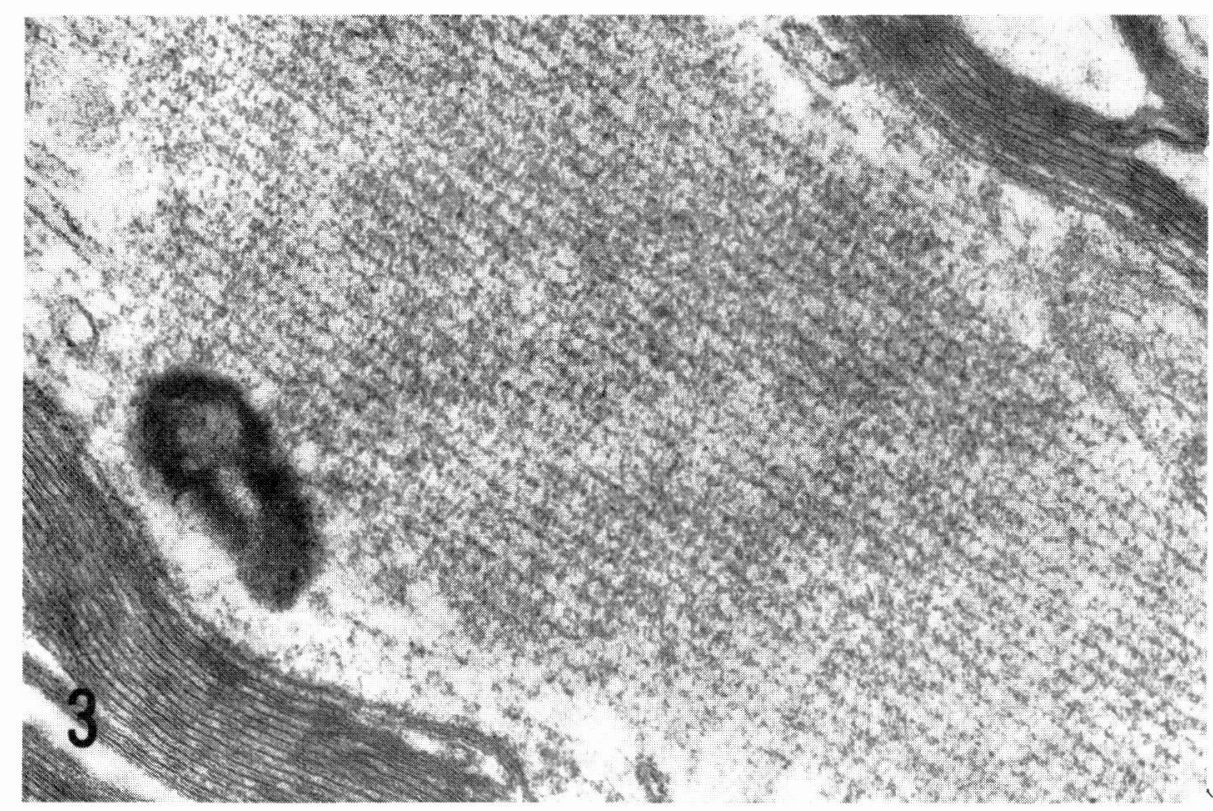

Fig. 3 A longitudinally sectioned crystal reveals clearly row of dots. A portion of myelinated axon in the medulla. $\times 65,000$ 


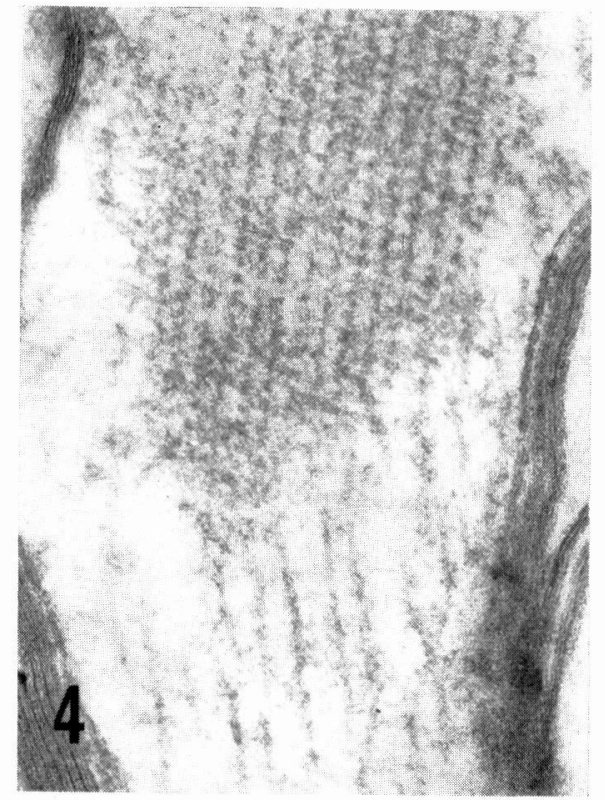

Fig. 4 Longitudinal section of a intraaxonal crystal. A apparent continuity between the neurofilament and the row of crystal. $\times 75,000$

These tubular structures were highly regular, and thus fulfilled the requirements for the definition of a crystal.

In longitudinal section the crystalline mass appeared to be composed of regular parallel array of electron dense line measuring $100 \AA$ in diameter. Each electron opaque orderline which ran parallel to the long axis of the crystal, was separated from adjacent ones by periodical interval of 220 to $250 \AA$.

When the fine structure of the line was examined at higher magnification, they were consisted of line of osmiophilic dots which were in rows side by side. The distance of periodic interval of dots forming a line measured aproximately 220 to $240 \AA$.

In some instances the end of rows of the longitudinal sectioned crystalline bodies has continuity with the neurofilaments. As indicated by electron

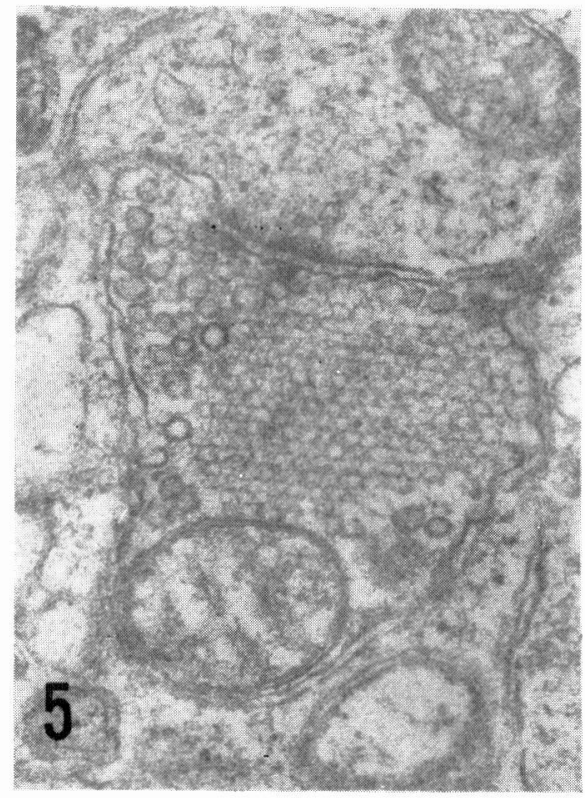

Fig. 5 Presynaptic axon terminal containing a crystal. Pons. $\times 43,000$

micrograph, there were no special relationships between these crytalline mass and intracellular organelles such as, mitochondria, Golgi complex or endoplasmic reticulum. In addition to crystal, the more interesting finding was the disappearance of normal neurotubules with increasing of neurofilaments in affected neuron. In the presynaptic axon terminal, the crystalline bodies also could be frequently observed.

Rarely, the crystalline mass which revealed a checkerboard pattern, occupied almost of presynaptic sac. In enlarged presynaptic axon terminal, one or several crystals push synaptic vesicles away peripherally.

\section{DISCUSSION}

In 1961 Smith firstly observed special 
tubular structure in experimental cretinism in rat and called it "membranous inclusion" 16). Since his report, similar structures have been demonstrated by several investigators in normal or pathological condition.

Duncan also noted "precise order" structure in the granular cortex of the cerebellum of normal animals ${ }^{4}$, and however, had a doubt that this peculiar structure should result from artefact of fixation. Hirano also raised same question at the beginning of his study of these special structure which was named as "honeycomb like tubular structure"6).

In order to solve above question, he used different fixative material and technique. Finaly he however, believed that their occurrence would not seem to be dependent upon perfusion-fixation methods. In our preliminary experiment utilizing the perfusion technique, they were obsevable in proportion to dose of vincristine and were not found in control group. According to the finding obtained here we would also agree with Hirano's conclusion concerning the nature of these crystal.

Aside from discussion whether artifactual or real structure, Raine and Field on the other hand, found orientated tubules in axoplasm of myelinated fibre in normal and scrapie animal ${ }^{5111}$. They appeared more frequent in the oldest animal. According to morphological resemblances of scrapie to those of old age, Raine also speculated that both scrapie and ageing might have common basic process. It has been well known that the viruses revealing an intracytoplasmic development had the tendency to form various type of crystal. Recently Tani has also described polyhedral crystalline structure in human glioma ${ }^{17)}$. Therefore one may assume that crystalline mass revealing a honeycomb like structure in cross section, is composed of virus particles. Reine noted that crystal in scrapie might be an arrangement of virus particles associated with an expanded reticular array. However, Hirano and Duncan ignored them in relation to virus. In our experiment we had no evidence for a virus infection. If the crystalline structure were viral in nature, many more should be observed in the normal animal. It is difficult to consider that such a peculiar structure should originate from virus. At higher magnification of the crystalline array demonstrated here, they appeared to be somewhat different from those so far previously reported by others. Firstly they had no continuity with endoplasmic reticulum as stated by Hirano. Secondary, ribosome or dense particle was not visible in the crystalline subunit in our cases.

Vincristine-induced crystal in neuron, therefore, did not come from intracellular membranous organelles such as rough or smooth endoplasmic reticulum and golgi complex. Lampart et al. found them only in dystrophic axons caused by vitamin $\mathrm{E}$ deficiency and some authors considered them as specific or non specific axonal response to unknown condition. We consider that the special tubular structure hitherto reported is originated from endoplasmic reticulum, presumably in response to axonal injury. In addition to the presence of the crystalline mass, more important neuronal changes were of disappearance of normal neurotubules and overproduction of neurofibril. Vincristine is effective in a wide range of solid tumors and leukemia in children, and a potent mitotic inhibitor as same as colchicine. Proliferation of filament in response to colchicine has been reported in HeLa cell ${ }^{12)}$. Recently, colchicine has been shown to exert its antimitotic action by binding to the protein of the mitotic spindle tubule 2) 3) 14). This binding has 
been demonstrated to occur to other microtubules which is analogous of the neurotubules ${ }^{1 / 15}$. These findings indicated that neurotubules and spindle tubules are homologous structures with regard to their susceptibility to break down by vincristine. It seems relevant to note that the spindle inhibitor such as vincristine and colchicine, break down normal neurotubles or rearrange the molecule of neurotubule protein.

The destructed or rearranged neurotubule probably may form bundles of neurofilaments. However, if animal was treated with higher dose of vincristine, proliferated neurofilament or neurotubules appeared to form the crystal.

If the lower dosage of vincristine, the more scattering filament might be visible within neuron. It seems that the crystals result from a helical arrangement of the neurofilament. In addition to these theoretical consideration, more direct evidence was provided by, the finding that continuity could be seen between the neurofilament and the end of the row of crystal cut longitudinally. It is reasonable to consider that the crystalline structure must be one of the transitional form between neurotubule and neurofilament which result from breakdown of the neurotubules.

Acknowledgment: We wish to thank Prof. $K$. Inanaga for his guidance and advice in the study, and also Miss S. Nishida for her technical assistance.

\section{REFERENCES}

1) Adelman; M. R.: Cytopläsmic filaments and tubles, Fed Proc, 27, 1186, 1968

2) Borisy, G. G. and TAYLOR, E. W. : The mechanism of action of colchicine : colchicine binding to sea urchin eggs and the mitotic apparatus, J. Cell Biol. 34, 535, 1967.
3) Borisy, G. G. and TAYloR, E. W. : The mechanism of action of colchicine : binding of colchicine $\mathrm{H}$ to cellular protein. J. Cell Biol. 34, 525, 1967.

4) Duncan, D. and Williams, V.: On the occurrence of a precise order in axoplasm. Tex. Rep. Biol. Med. 20, 503, 1962.

5) Field, E. J. and Joyce, G. : An electron microscopic study of scrapie in the rat.

I. The occurrence of amyloid bodies and deposits. Acta neuropath. (Berl.) 9, 305, 1967.

6) Hirano, A., Rubin, R., Sutton, C.H. and Zimmerman, H. M. : Honeycomb-like tubular structure in axoplasm, Acta neuropath. 10, 17, 1968.

7) Lampert, J. M., Blumberg, J. M. and Pentschew, A.: An electron microscopic study of dystrophic axons in the gracile and cuneate nuclei of vit. Edeficient rats. J. Neuropath. exp. Neurol. 23, 60, 1964.

8) LufT, J.: Improvements in epoxy resin embedding methods. J. biophys. biochem. Cytol. 9, 409, 1964.

9) Millonig, G. : Further observations on a phosphate buffer for osmium solution in fixation. In proceeding of the fifth international cogress for electron microscopy, edited by Breese, S.S., Vol. 2, p. 2, New York, Academic Press, Inc., 1962.

10) Mori, H.: An electron microscopic study in encephalomyelopathy induced by vincristine-Experimental neurofibrillary change. In Press. Kyushu N-Psych.

11) Raine, C. S. and Field, E. J. : Orientated tubules in axoplasm of cerebellar myelinated nerve fibres in the rat. Acta neuropath. $9: 298,1967$.

12) Robbins, E. and Gonatas, N. K. : Histochemical and ultrastructural studies on HeLa cell cultures exposed to spindle inhibitors with special reference to the interphase cell. J. Histochem. Cytochem. 12, 704, 1964.

13) Schochet, S. S., Lampert, P. W. and Earle, K. M. : Neuronal changes induced by intrathecal vincristine sulfate. J. Neuropath. exp. Neurol., 27, 645, 1968.

14) Shelanski, M. L. and TAYLOR, E. W.: Isolation of a protein subunit from microtubules, J. Cell Biol. 34, 549, 1967.

15) Shelanski, M. L. and Wisniewski, H. : Neurofibrillary degeneration, Arch. Neu- 
rol. 20, 199, 1969.

16) Sмiтh, K. R. : Experimental cretinism in rats. Neurology (Minneap.). 11, 470, 1961.

17) Tani, E., Yamashita, J., Takeuchi, J. and HANDA, H.: Polygonal crystalline structure and crystalline aggregates of cylind- rical particles lin human glioma. Acta neuropath. (Berl.). 13, 324, 1969.

18) Yoshida, N., Tomita, Y. and Misaka, Y. : On characteristic structures seen in the reticular formation core, Kurume med. J., 12, 155, 1965. 